\title{
PCCP
}

PAPER

Received 00th January 20xx, Accepted 00th January 20xx

DOI: $10.1039 / x 0 \times x 00000 x$

www.rsc.org/

\section{Mitigated phase transition during first cycle of a Li-rich layered cathode studied by in operando synchrotron X-ray powder diffraction $\dagger$}

\author{
Bohang Song, ${ }^{a,+}$ Sarah J. Day, ${ }^{b}$ Tan Sui, ${ }^{a}$ Li Lu, ${ }^{c}$ Chiu C. Tang, ${ }^{b}$ Alexander M. Korsunsky ${ }^{a}{ }^{*}$
}

\section{Introduction}

Lithium-rich layered oxides have drawn extensive interest as cathode materials worldwide over the past decade in the field of lithium-ion batteries (LIBS). The nature of these materials leads to a high reversible capacity of over $250 \mathrm{mAh} \cdot \mathrm{g}^{-1}$ compared to $120 \mathrm{mAh} \cdot \mathrm{g}^{-1}$ of commercialized $\mathrm{LiCoO}_{2}$, acceptable thermal and structural stability, and low cost ${ }^{1}$. However, one of the critical issues that must be addressed prior to full scale utilization as a cathode in LIBs is the so-called "voltage decay", which is believed to be associated with the phase transformation inside individual particles that occurs in the very first cycle. It leads to voltage drop upon cycling, and thus the loss of the stored energy density of the whole battery system. The main phase in these Li-rich cathode materials is the rhomboheral $\mathrm{LiMO}_{2}(\mathrm{M}=\mathrm{Ni}, \mathrm{Co}$, and/or $\mathrm{Mn})$ that is accompanied by the monoclinic $\mathrm{Li}_{2} \mathrm{MnO}_{3}$ phase. The phase transformation mechanisms in these systems have been systematically studied in recent years ${ }^{2-5}$. Armstrong et al. ${ }^{6}$ first demonstrated oxygen loss in association with Li removal in the compositional ratio of $\mathrm{Li}_{2} \mathrm{O}$, and the consequent structural reorganization upon the $1^{\text {st }}$ charge/discharge cycling that is triggered by the transition metal (TM) migration from transition metal layer to a lithium layer vacancy. Gu et al. ${ }^{7}$

\footnotetext{
MBLEM, Department of Engineering Science, University of Oxford, Oxford OX 3PJ, UK.

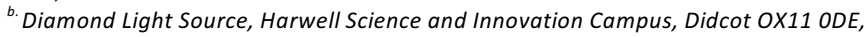
UK.

National University of Singapore, Department of Mechanical Engineering, Singapore.

+ Current address: University of Texas at Austin, U.S.A.

$\uparrow$ Electronic Supplementary Information (ESI) available: Morphology and electrochemical performance of $\mathrm{P}$ - and C-type cathodes, domain size and microstrain variations during high rate cycling. See DOI: 10.1039/x0xx00000x
}

investigated the spinel formation in view of two different phases (rhomboheral $R \overline{3} m$ and monoclinic $C 2 / m$ ) by performing aberration-corrected scanning transmission electron microscopy (STEM) and electron energy loss spectroscopy (EELS). The results showed that the transformation in the $R \overline{3} \mathrm{~m}$ phase started from the surface and proceeded into the bulk of particles, and was accompanied by TM migration, and the nucleation and growth of spinel, whilst the transformation in the $C 2 / \mathrm{m}$ phase was triggered by the oxygen loss and subsequent nano-nucleation of spinel-like nano-domains, as well as the formation of an amorphous phase in bulk. Gallagher et al. ${ }^{8}$ first demonstrated through a systematic electrochemical study the two steps of TM migration from a metastable tetragonal site to a localized and lower energy site to initiate spinel formation, which could be visualized from the hysteretic voltage decay.

A lot of effort has been dedicated to countering this spinel transformation to suppress the voltage decay which seems to be an inherent nature of Li-rich layered cathodes. Croy et al. ${ }^{9}$ proposed a "layered-rocksalt" composite, $x \mathrm{Li}_{2} \mathrm{MnO}_{3} \cdot(1-x) \mathrm{MO}$ (where $\mathrm{M}$ refers typically to $\mathrm{Mn}, \mathrm{Ni}$, and/or $\mathrm{Co}$ ), to stabilize the local structure without compromising capacity, and achieved $245 \mathrm{mAh} \cdot \mathrm{g}^{-1}$ between 4.4 and $2.5 \mathrm{~V}$ at $15 \mathrm{~mA} \cdot \mathrm{g}^{-1}$ after 60 cycles without obvious voltage decay. Recently, Sathiya et al. ${ }^{10}$ reported a series of novel $\mathrm{Li}_{2} \mathrm{Ru}_{1-\mathrm{y}} \mathrm{Sn}_{\mathrm{y}} \mathrm{O}_{3}$ cathodes with enhanced structural stability, which demonstrated a possible route to slow down the $T d$ (tetrahedral position next to the $\mathrm{LiM}_{2}$ layers) trapping by introducing large separator ions such as Sn. When Sn ratio increased from 25 to 50\%, 50\% decrease of voltage decay was reported in $\mathrm{Li}_{2} \mathrm{Ru}_{0.5} \mathrm{Sn}_{0.5} \mathrm{O}_{3}$. Zheng et al. ${ }^{11}$ compared different synthesis methods and minimized the inhomogeneity of $\mathrm{Ni}$ distribution at the particle surface, which has proven to be beneficial for the suppression of voltage decay. Lee et al. ${ }^{12}$ systematically investigated the effects of the 

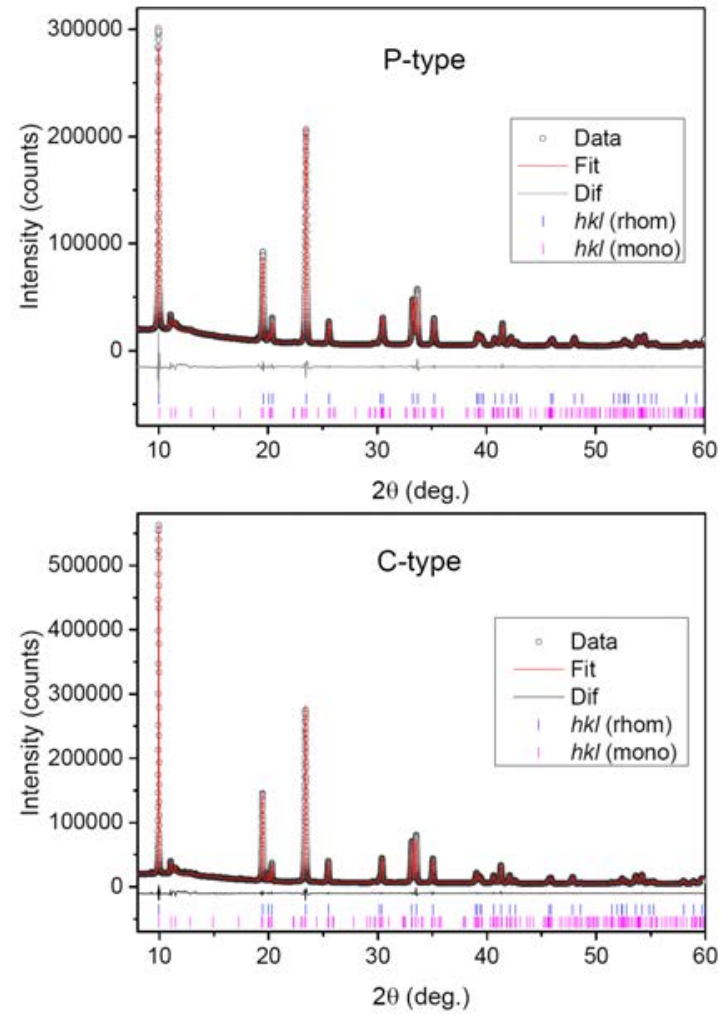

Fig. 1 SXPD patterns, fitted and difference data of P-and C-type powder materials and $h k l$ reflections of the rhomboheral and monoclinic phases are presented as vertical lines below the difference curves.

$4.5 \mathrm{~V}$ plateau length on the extent of voltage decay and found that the most suitable cathode composition of $\mathrm{Li}_{1.15} \mathrm{Mn}_{0.54} \mathrm{Ni}_{0.23} \mathrm{Co}_{0.08} \mathrm{O}_{2}$ could be achieved without sacrificing much of the discharge capacity. Ates et al. ${ }^{13}$ also reported an effective strategy to mitigate this voltage decay by partial substitution of $\mathrm{Li}^{+}$ions with $\mathrm{Na}^{+}$, producing the $0.3 \mathrm{Li}_{2} \mathrm{MnO}_{3} \cdot 0.7 \mathrm{Li}_{0.97} \mathrm{Na}_{0.03} \mathrm{Mn}_{0.33} \mathrm{Ni}_{0.33} \mathrm{Co}_{0.33} \mathrm{O}_{2}$ composition. According to the more recent work by Song et $\mathrm{al}^{14}, \mathrm{Cr}$-doping at the Co-site in Li-rich layered cathodes has benefits in mitigating the local phase transition by shortening the $4.5 \mathrm{~V}$ charging plateau, without sacrificing much reversible capacity due to $\mathrm{Cr}^{3+/ 6+}$ redox compensation.

To acquire further insights into the structural stabilization mechanisms, pristine $\mathrm{Li}\left(\mathrm{Li}_{0.2} \mathrm{Ni}_{0.13} \mathrm{Mn}_{0.54} \mathrm{Co}_{0.13}\right) \mathrm{O}_{2}$ (P-type) and Cr-doped $\mathrm{Li}\left(\mathrm{Li}_{0.2} \mathrm{Ni}_{0.13} \quad \mathrm{Mn}_{0.54} \mathrm{Co}_{0.03} \mathrm{Cr}_{0.10}\right) \mathrm{O}_{2}$ (C-type) cathodes were studied while cycling at both slow and fast rates using in operando synchrotron X-ray powder diffraction (SXPD). It is well known that both the rhomboheral $R \overline{3} m-\mathrm{LiMO}_{2}$ and the monoclinic $\mathrm{C} 2 / m-\mathrm{Li}_{2} \mathrm{MnO}_{3}$ phases possess the $\alpha-\mathrm{NaFeO}_{2}$-type of structure with a cubic-close-packed oxygen array, with all of

Table 1 Lattice parameters of the as prepared P- and C-type samples.

\begin{tabular}{|c|c|c|c|c|c|c|}
\hline \multirow[b]{2}{*}{ Sample } & \multicolumn{2}{|c|}{$R \overline{3} \mathrm{~m}$} & \multicolumn{4}{|c|}{$C 2 / \mathrm{m}$} \\
\hline & $\mathrm{a}(\AA ̊)$ & b (Å) & a $(\AA ̊)$ & $b(\AA ̊)$ & $c(\AA)$ & $\beta\left(^{\circ}\right)$ \\
\hline P-type & $\begin{array}{c}2.8512 \\
1(1)\end{array}$ & $\begin{array}{c}14.225 \\
6(1)\end{array}$ & $\begin{array}{c}4.9761 \\
(6)\end{array}$ & $\begin{array}{c}8.5252 \\
\text { (9) }\end{array}$ & $\begin{array}{c}4.9966 \\
(5)\end{array}$ & $\begin{array}{c}109.52 \\
5(9)\end{array}$ \\
\hline C-type & $\begin{array}{c}2.8634 \\
7(1)\end{array}$ & $\begin{array}{c}14.279 \\
2(2)\end{array}$ & $\begin{array}{c}4.9890 \\
(2)\end{array}$ & $\begin{array}{c}8.5541 \\
(4)\end{array}$ & $\begin{array}{c}5.0353 \\
(2)\end{array}$ & $\begin{array}{c}109.36 \\
1(2)\end{array}$ \\
\hline
\end{tabular}

the octahedral sites occupied by Li and transition metals. This is the reason why their diffraction peaks are similar to each other, the only difference being due to the (020) and (110) peaks in the $C 2 / \mathrm{m}$ phase. Whether this family of Li-rich layered cathodes are in the form of solid solution or composite structure, however, is still under debate. The most acceptable model is the nano-composite structure proposed by Thackeray et al. ${ }^{1}$ and also reported by other groups ${ }^{15-16}$. In this model, there are $\mathrm{Li}_{2} \mathrm{MnO}_{3}$-like and $\mathrm{LiMO}_{2}$-like nano-domains with short-range ordering in each domain due to the lack of Li-ions in the transition metal layer to sustain exact ratio of Li:TM at $1: 2$. In the current study, the diffraction data from powder samples was interpreted by two-phase refinement to allow quantitative analysis of the lattice structure and phase composition. For the in operando diffraction data during cycling, only the majority phase $R \overline{3} m$ was refined, similarly to most of the studies reported in the literature ${ }^{4,17-19}$. This is due to the fact that the majority of diffraction peaks of the $R \overline{3} \mathrm{~m}$ and $\mathrm{C} 2 / \mathrm{m}$ phases are coincident between the two phases, with only $(020)$ and $(110)$ peaks being belonging to the $\mathrm{C} 2 / \mathrm{m}$ phase only. Furthermore, upon cycling the intensity of the (020) and (110) $\mathrm{C} 2 / \mathrm{m}$ peaks gradually reduces due to the loss of the $\mathrm{LiMn}_{6}$ superlattice that accompanies the removal of $\mathrm{Li}$ from structure.

\section{Experimental}

\section{Preparation of battery materials and coin cells}

Both pristine and $\mathrm{Cr}$-doped cathode samples were synthesized by combining co-precipitation and solid-state reaction methods. The technical details of the process has been reported in our previous paper ${ }^{14}$. Scanning electron microscopy (SEM) images of each type of material are shown in Fig. S1 to demonstrate their morphologies and various particle sizes. To prepare the electrode slurry, active particles, carbon black (Super P), and Polyvinylidene Fluoride (PVDF) were homogeneously mixed together in a n-methyl-2pyrrolidone (NMP) solution, in the weight ratio of $80: 10: 10$. The slurry was then pasted onto an Al foil ( $25 \mu \mathrm{m}$ thickness) before drying overnight to make it ready as an electrode. This electrode typically has the active material loading density of 5 6 $\mathrm{mg} / \mathrm{cm}^{2}$.

Each synthesised material was loaded and tested using a normal battery coin cell. Fig. $\mathrm{S} 2$ demonstrates the suppression of voltage decay in the discharge curves from $1^{\text {st }}$ to $60^{\text {th }}$ cycle of Cr-doped cathode compared to the pristine material, whereas the specific capacities of these two are still comparable. For the synchrotron measurements, modified coin cells with $\mathrm{X}$-ray windows at both beam entry and exit were used to assemble the lithium-ion batteries. For good $X$ ray transmission, thin $\mathrm{Al}$ foils $(25 ! \mathrm{m} \times 2)$ were used as $X \quad$-ray windows. The P-and C-type battery cells were cycled between 4.9 and $1.5 \mathrm{~V}$ at low $\left(50 \mathrm{~mA} \cdot \mathrm{g}^{-1}\right)$ and high $\left(250 \mathrm{~mA} \cdot \mathrm{g}^{-1}\right)$ current density to compare the effects of electrochemical reactions.

\section{In operando synchrotron $X$-ray diffraction experiments}






Fig. 2 Evolution of the X-ray diffraction patterns of P-type battery during $1^{\text {st }}$ cycling at $50 \mathrm{~mA} \cdot \mathrm{g}^{-1}$. The enlarged parts (right) represent the evolution of the (003) and (101) peaks.

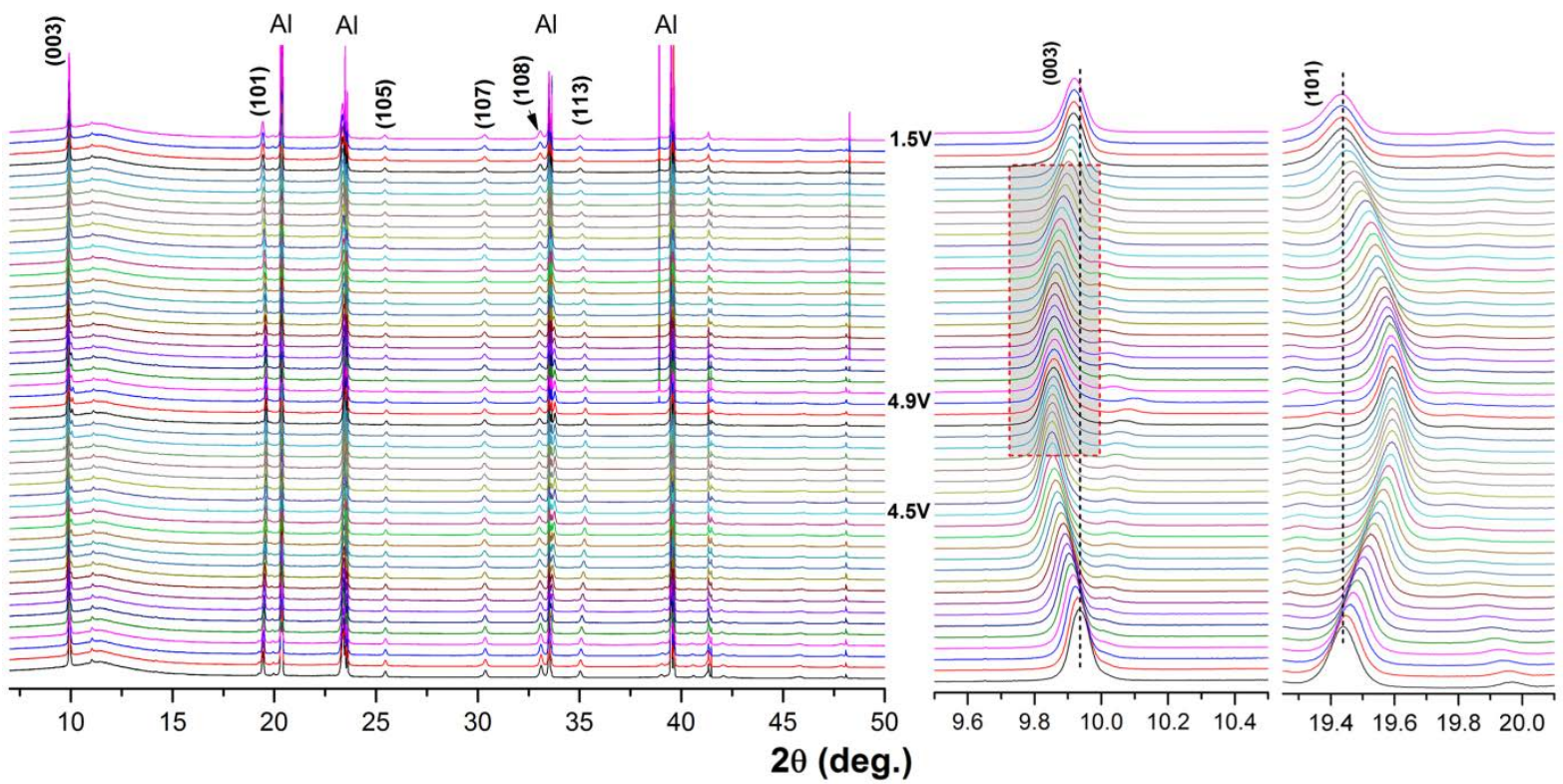

Fig. 3 Evolution of the X-ray diffraction patterns of C-type battery during 1st cycling at $50 \mathrm{~mA} \cdot \mathrm{g}-1$. The enlarged parts (right) represent the evolution of (003) and (101) peaks.

During charge cycling, SXPD patterns were obtained using beamline 111 at Diamond Light Source (UK). The technical details for the instrument are given elsewhere ${ }^{20-21}$. All measurements were performed in transmission mode using a monochromatic beam of $E=15 \mathrm{keV}$. The wavelength was precisely calibrated using a high quality reference standard of NIST Si powder (SRM640c) to be $\lambda=0.825985(10) \AA$. The high brightness incident beam and position-sensitive detector (PSD) permitted fast data collection at $20 \mathrm{~s} /$ pattern. A pattern was collected every $10 \mathrm{~min}$ during the $1^{\text {st }}$ cycle of $50 \mathrm{~mA} \cdot \mathrm{g}^{-1}$ and $250 \mathrm{~mA} \cdot \mathrm{g}^{-1}$ charge/discharge rate of the two batteries. The data were analysed using TOPAS analysis software ${ }^{22}$. Several strong peaks were observed in the patterns using the battery cells, which correspond to Al foils (windows and electrode support) and have been excluded in the refinements. Although full Rietveld refinement was not possible due to the overlaps between active materials and Al peaks, the unit cell parameter evolution could be monitored by whole pattern Pawley refinement. It provides an understanding of the unit cell distortion mechanism, as $a$ and $b$ parameters correspond to the slab dimensions, and $c$ corresponds to the inter-slab distance. In addition, the broadening of diffraction peaks was de-convoluted from the instrumental contributions using Fundamental Parameters (FP) method $^{23}$ to extract the apparent particle, crystal or domain sizes, and micro-strain, together with the crystallographic details.

\section{Results and discussion}

\section{Phase Characterisation Using High Resolution SXPD}




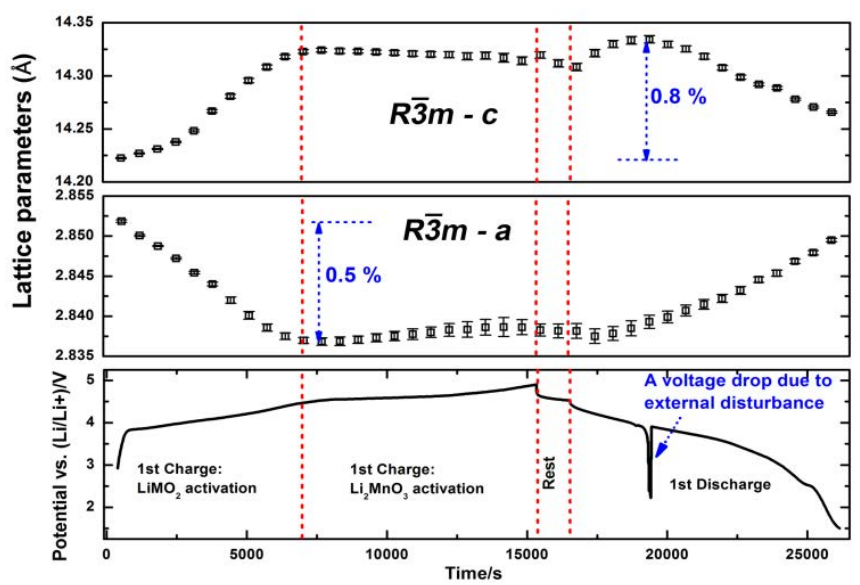

Fig. 4 Evolution of the lattice parameters of P-type during $1^{\text {st }}$ cycling at $50 \mathrm{~mA} \cdot \mathrm{g}^{-1}$.

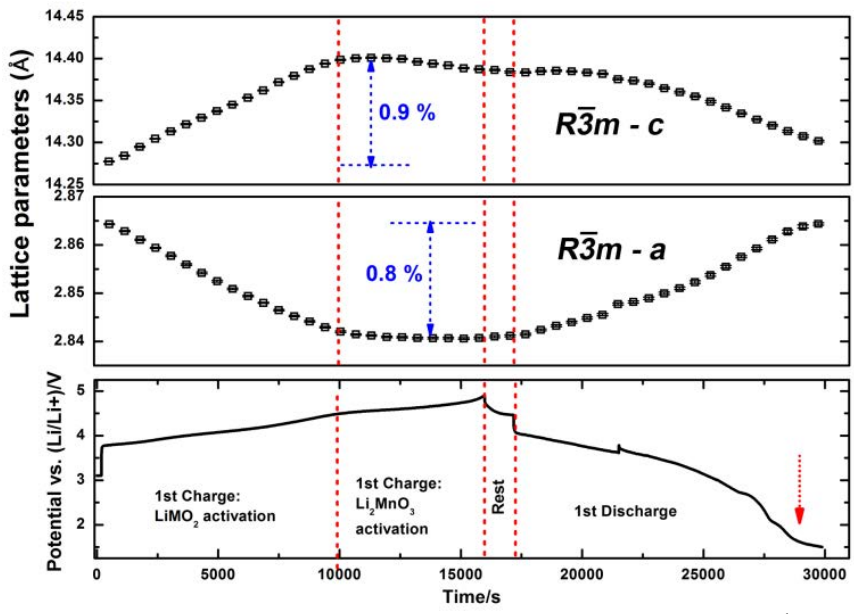

Fig. 5 Evolution of the lattice parameters of C-type during $1^{\text {st }}$ cycling at $50 \mathrm{~mA} \cdot \mathrm{g}^{-1}$.

As prepared samples were loaded in $0.5 \mathrm{~mm}$ diameter borosilicate capillaries and characterised with a $10 \mathrm{~s}$ SXPD pattern each. The experimental data and fitted results are shown in Fig. 1 . The main peaks for both active materials ( $\mathrm{P}$ - and $\mathrm{C}$-type) could be indexed as belonging to the $\mathrm{LiNi}_{1 / 3} \mathrm{Co}_{1 / 3} \mathrm{Mn}_{1 / 3} \mathrm{O}_{2}$ phase with $R \overline{3} m$ space group. In addition, the minor phase of $\mathrm{Li}_{2} \mathrm{MnO}_{3}(\mathrm{C} 2 / \mathrm{m})$ was also present in both cathodes. As can be seen from Fig. 1, both patterns were fitted well with Rwp $=4.27$ and $4.06 \%$ for the P- and C-type samples, respectively. The lattice parameters of the rhombohedral and monoclinic phases were obtained and are summarised in Table 1 for comparison. It should also be pointed out that the crystallographic results for the $\mathrm{Li}_{2} \mathrm{MnO}_{3}$ phase may not be reliable due its most intense peaks being superimposed with those from the R-3m structure. Only using a few weak peaks $\left(11-15^{\circ} 2 \theta\right.$ in Fig. 1) for the refinements could result in producing poor accuracy parameters. It is therefore difficult to crystallographically distinguish the minor $\mathrm{C} 2 / \mathrm{m}$ phase from the major $\mathrm{R}-3 \mathrm{~m}$ phase, in particular using the operando data (next section) which included additional peaks from the Al-windows. We therefore only included the results from the refinements for the $\mathrm{LiNi}_{1 / 3} \mathrm{Co}_{1 / 3} \mathrm{Mn}_{1 / 3} \mathrm{O}_{2}$ as we with have no confidence with those obtained for the $\mathrm{Li}_{2} \mathrm{MnO}_{3}$.

\section{In operando analysis - Low Charge Rate}

The evolution of in situ SXRD patterns of P- and C-type during electrochemical cycling is shown in Figs. 2 and 3 . The $(h k l)$ peaks labelled in the figure correspond to the $R \overline{3} m$ space group. As shown in the enlarged patterns, the evolution of the (003) peak shows a difference between the pristine and $\mathrm{Cr}$ doped cathodes. For the P-type battery, this peak shifts slightly toward the lower angle and exhibits significant broadening, starting from early stage of charging to the end of discharge. Such broadening of peaks could be ascribed to two reasons, the first of which is the extension of disordered phase and stacking faults during (de)intercalation of Li. The second is the nucleation and growth of a new phase, as suggested by the splitting of the (003) peak when charging to around $4.5 \mathrm{~V}$, and emphasized by the grey rectangle in the enlarged patterns of Fig. 2. If the latter mechanism dominates, then this observation is quite consistent with previous reports on the lattice rearrangement from layered to spinel-like ordering, which also involves TM migration from the TM layer to the $\mathrm{Li}$ layer ${ }^{6-7}$. Interestingly, in the $\mathrm{Cr}$ doped sample, the (003) peak shifts significantly to a lower angle but with less broadening of peaks during charge/discharge, as emphasized by the grey rectangle in enlarged patterns of Fig. 3 , indicating relatively small structural change in the local lattice as a result of (de)intercalation of $\mathrm{Li}$. This observation implies enhanced stability, and better reversibility of $\mathrm{Cr}$-doped material. The better reversibility could also be identified in terms of the evolution of (003) and (101) peaks which are associated with the $a$ and $c$ lattice parameters, respectively. They are seen to evolve in opposite directions during cycling: the (101) peak shifts from higher angle back to its original position in the case of C-type during discharge, whereas it only partially shifts back under the same conditions for the P-type sample. It is speculated that $\mathrm{Cr}$-doping stabilizes and/or tunes the electronic configurations of the $C 2 / m$ phase, with only partial activation of it as a consequence. Meanwhile, the deintercalation of $\mathrm{Li}$ accompanied with $\mathrm{Cr}^{3+}$ oxidation to $\mathrm{Cr}^{6+}$ may suppress the $\mathrm{O}^{2-}$ oxidation reaction to $\mathrm{O}^{-24-25}$. This finding may provide an explanation of why $\mathrm{Cr}$-doping has benefits in mitigating the voltage decay in subsequent cycles, as reported by Song et al. ${ }^{14}$. Note that the $C 2 / m$ phase activation with a removal of $\mathrm{Li}_{2} \mathrm{O}$ is the main reason for the phase transition and voltage decay. Such mechanism change as mentioned above of $\mathrm{Li}$ removal from the $\mathrm{C} 2 / \mathrm{m}$ phase is also the reason why $\mathrm{Cr}$ doping of the cathode shortens the length of the $4.5 \mathrm{~V}$ plateau, as will be shown in Figs. 4 and 5. It is also worth pointing out that the activation depths of both P-and C-type electrodes must be comparable and have similar effects on reversibility. In fact, the C-type delivers more discharge capacity, meaning that more active particles take part in the electrochemical reaction than $\mathrm{P}$-type, therefore leading to better reversibility. Fig. 4 shows the evolution of the $a$ and $c$ lattice parameters of P-type cathodes during the $1^{\text {st }}$ cycle, with charging and discharging stages labelled. During the $1^{\text {st }}$ charge activation of $R \overline{3} \mathrm{~m}$ phase from open circuit voltage (OCV) to $4.5 \mathrm{~V}$, the $a$ parameter gradually decreases, which is commonly related to the oxidation of transition metals in the TM layer resulting in reduced atomic radii. Meanwhile, the $c$ parameter gradually increases, which is regarded to be the result of Li removal from metallic layer, leading to a decrease of the screening effect between the oxygen layers. At the second stage of the $1^{\text {st }}$ 


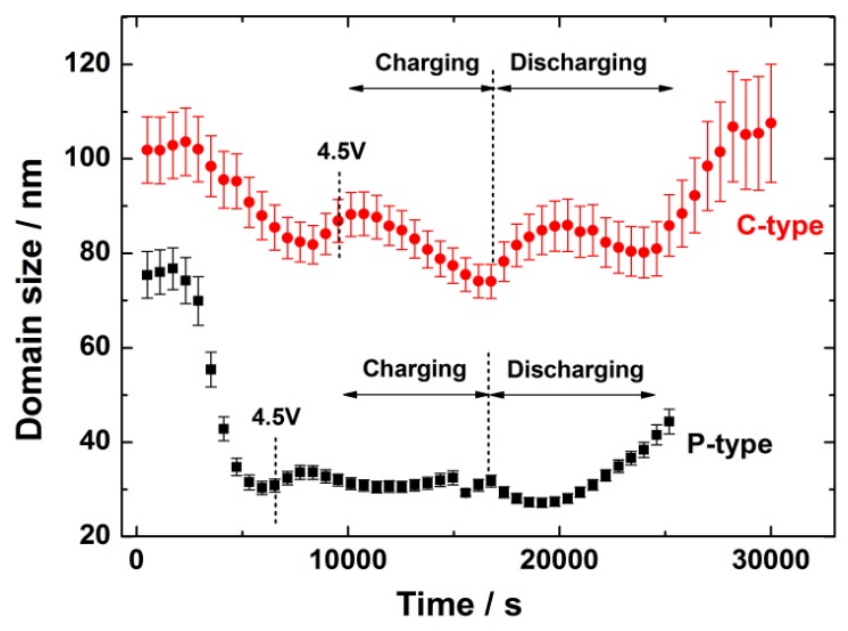

Fig. 6 Domain size variations during first charge/discharge cycle of both pristine and $\mathrm{Cr}$ doped cathodes at $50 \mathrm{~mA} \cdot \mathrm{g}^{-1}$.

charging, i.e. the activation of the $\mathrm{C} 2 / \mathrm{m}$ phase, both $a$ and $c$ lattice parameters of the $R \overline{3} \mathrm{~m}$ phase remain stable showing no obvious variation, although $\mathrm{Li}$ is further extracted from the local structure. This behaviour is commonly regarded as a biphasic process, which is consistent with the plateau observation from the charging curve ${ }^{26}$. During the $1^{\text {st }}$ discharging stage, both $a$ and $c$ parameters of the $R \overline{3} m$ phase tend to recover back to their original value, meaning a partially-reversible process of Li reinsertion. In contrast, the Ctype cathode shown in Fig. 5, exhibits similar tendencies for the $a$ and $c$ parameters of the $R \overline{3} m$ phase, but better reversibility in terms of the close value of lattice parameters between fresh and the $1^{\text {st }}$ discharged state. Besides, comparing the variation ratios of lattice parameters upon the $1^{\text {st }}$ cycle for P- and C-type cathodes also indicates a similar value of their maximum relative change due to (de)intercalation of Li from $R \overline{3} \mathrm{~m}$ phase.

The refined particle sizes are between $30-100 \mathrm{~nm}$, as shown in Fig. 6 . This is considerably smaller than the particles seen in the SEM images (Fig. S1). As X-rays only "see" diffraction entities, each particle must therefore contain smaller coherently scattering domains. We therefore refer to the size parameters deduced from diffraction (and hereafter) as crystallite or domain sizes. Fig. 6 compares the domain size evolution during the $1^{\text {st }}$ charge/discharge cycle between $\mathrm{P}$ - and C-type cathodes based on the results of FP-refinements. The domain size of pristine Li-rich material dramatically decreases from 75 to $30 \mathrm{~nm}$ that corresponds to the OCV and $4.5 \mathrm{~V}$ charging point. It implies a consistent change of domain size with the volume change of $R \overline{3} m$ phase as a result of deintercalation of Li. However, such decrease stops between 4.5 and the cut-off charging point of $4.9 \mathrm{~V}$ (the plateau region as indicated in Fig. 4). Note that both $a$ and $c$ lattice parameters of $R \overline{3} \mathrm{~m}$ phase exhibit almost no change in this voltage range according to Fig. $4\left(1^{\text {st }}\right.$ Charge: $\mathrm{Li}_{2} \mathrm{MnO}_{3}$

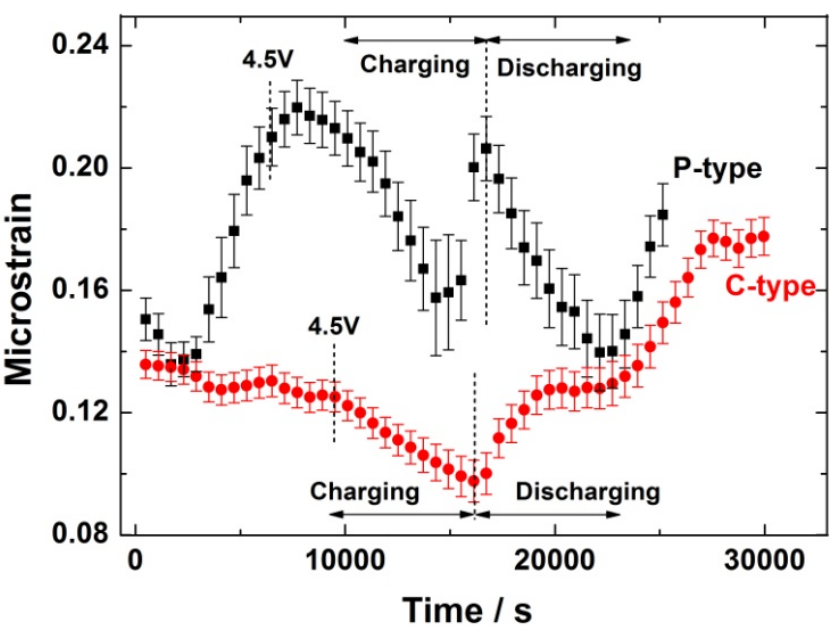

Fig. 7 Microstrain variations during first charge/discharge cycle of both pristine and $\mathrm{Cr}$ doped cathodes at $50 \mathrm{~mA} \cdot \mathrm{g}^{-1}$.

activation), suggesting again the domain size change is consistent with the volume change during activation. Upon discharge, the crystallites keep increasing from 30 to $44 \mathrm{~nm}$ due to the reinsertion of $\mathrm{Li}$ into lattice. On the other hand, after $\mathrm{Cr}$ doping, although the domain size of C-type reduces similarly from 100 to $80 \mathrm{~nm}$ due to Li removal from $R \overline{3} \mathrm{~m}$ phase, it continuously reduces further from 80 to $74 \mathrm{~nm}$ as a result of $\mathrm{Li}_{2} \mathrm{MnO}_{3}$ activation. This observation suggests again that the $\mathrm{Li}_{2} \mathrm{MnO}_{3}$ activation in $\mathrm{C}$-type cathode may possess a different reaction mechanism compared to $\mathrm{P}$-type, which is very likely to be related with the $\mathrm{Cr}^{3+/ 6+}$ redox reaction. On discharge, the domain size keeps increasing from 74 to $107 \mathrm{~nm}$ that is even bigger than the initial value.

Thus, it is important to point out two main findings:

(1) The decremental ratio of crystal size for C-type upon charging $(27 \%)$ is significantly less than the corresponding value of P-type (59\%).

(2) The domain size of C-type material is reversibly recovered upon the whole charge/discharge process, whereas P-type fails to recover fully. Both of these findings suggest a better reversibility of $\mathrm{Cr}$-doped Li-rich cathode compared to the pristine material as Li host structure.

Fig. 7 shows the microstrain variation of both P- and C-type cathodes upon the $1^{\text {st }}$ charge/discharge cycle. Such microstrain in domains could be ascribed to the high vacancy concentration during high temperature sintering, Li vacancy generation during (de)intercalation, lattice disorder, phase transition, etc. It is apparent that the microstrain evolution of C-type is coherent and reversible during the charge and discharge processes, whereas it is much more complex in the case of P-type. In addition, the highest value is 0.17 for the Ctype material, which is significantly less than 0.22 for the $\mathrm{P}$ type.

\section{In operando analysis - High Charge Rate}




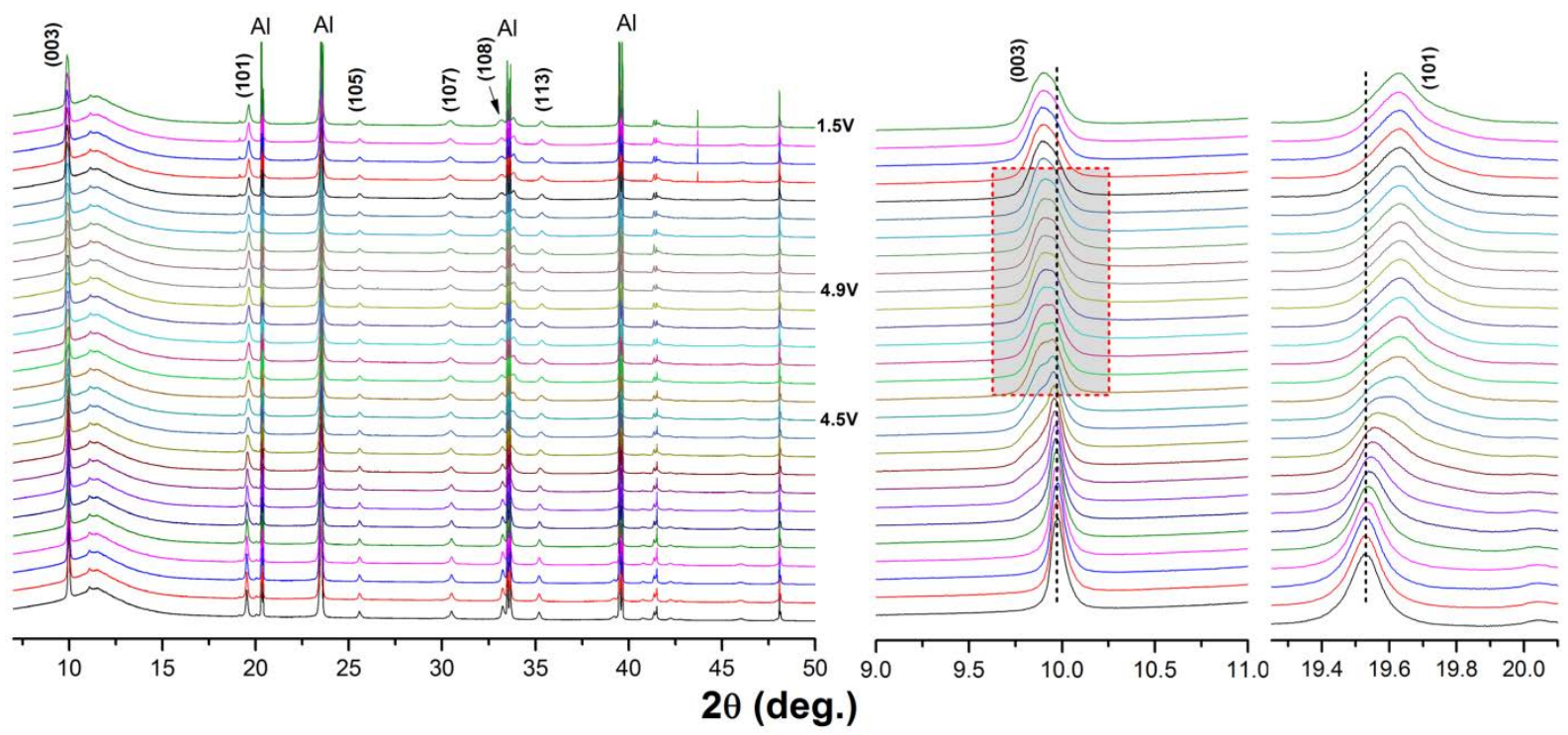

Fig. 8 Evolution of the SXPD patterns of P-type during $1^{\text {st }}$ cycling at $250 \mathrm{~mA} \cdot \mathrm{g}^{-1}$. The enlarged parts represent the evolution of (003) and (101) peaks.

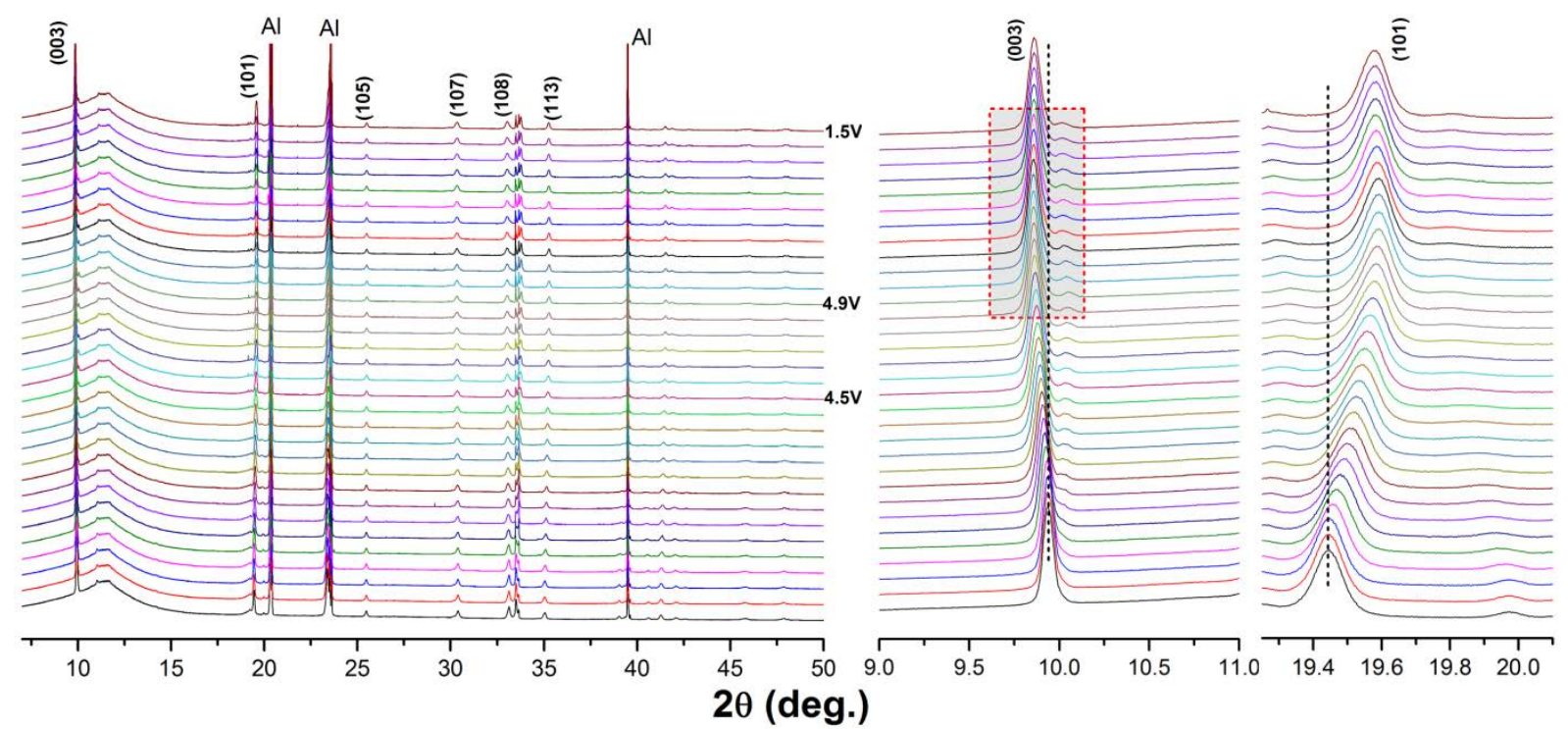

Fig. 9 Evolution of the SXPD patterns of C-type during $1^{\text {st }}$ cycling at $250 \mathrm{~mA} \cdot \mathrm{g}^{-1}$. The enlarged parts represent the evolution of (003) and (101) peaks.

To investigate the mechanism changes of the crystal structure due to high rate cycling, the current density was increased to $250 \mathrm{~mA} \cdot \mathrm{g}^{-1}$ and the in operando SXPD experiment was carried out for the two types of battery. The diffraction results for the P-type cathode are presented in Fig. 8. The (003) peak shifts to lower angle whilst the (101) peak shifts to higher angle upon $1^{\text {st }}$ charging process. However, it is apparent that they are not able to shift back upon $1^{\text {st }}$ discharge, indicating less reversibility of Li reinsertion at such a high current density. As in the low rate cycling, the splitting of the (003) peak was observed at about $4.5 \mathrm{~V}$ but was more pronounced, as highlighted by the grey region in the figure, suggesting an activation of the $\mathrm{Li}_{2} \mathrm{MnO}_{3}$ component and thus phase transition even at such a high rate. In contrast, the C-type cathode shows significant difference upon the $1^{\text {st }}$ cycle (Fig. 9). Specifically, the peak broadening of the (003) and (101) reflections is not obvious, with peaks remaining sharp and devoid of splitting when charging to voltages higher than $4.5 \mathrm{~V}$. In fact, these observations agree well with the charge curves shown in Figs. 10 and 11, since the $4.5 \mathrm{~V}$ charging plateau disappears in the case of C-type but still shows up for the Ptype. The reason might be that the reaction kinetics of removing $\mathrm{Li}$ from $\mathrm{Li}_{2} \mathrm{MnO}_{3}$ component in the C-type is even worse than the case of P-type because of $\mathrm{Cr}$ presence, or it could be due to the sluggish three-electron reaction of the $\mathrm{Cr}^{3+/ 6+}$ redox (Fig. S3).

Fig. 10 shows the variations of lattice parameters $a$ and $c$ for the $R \overline{3} \mathrm{~m}$ component of the P-type material when cycled at the high rate. During the first step of charging from OCV to $4.5 \mathrm{~V}$, both $a$ and $c$ parameters of the $R \overline{3} \mathrm{~m}$ phase change in accordance with the results at the low rate, indicating successful removal of Li from this phase. Upon discharging, both $a$ and $c$ lattice parameters only change slightly, which can be reasonably ascribed to the fast discharging rate that results 


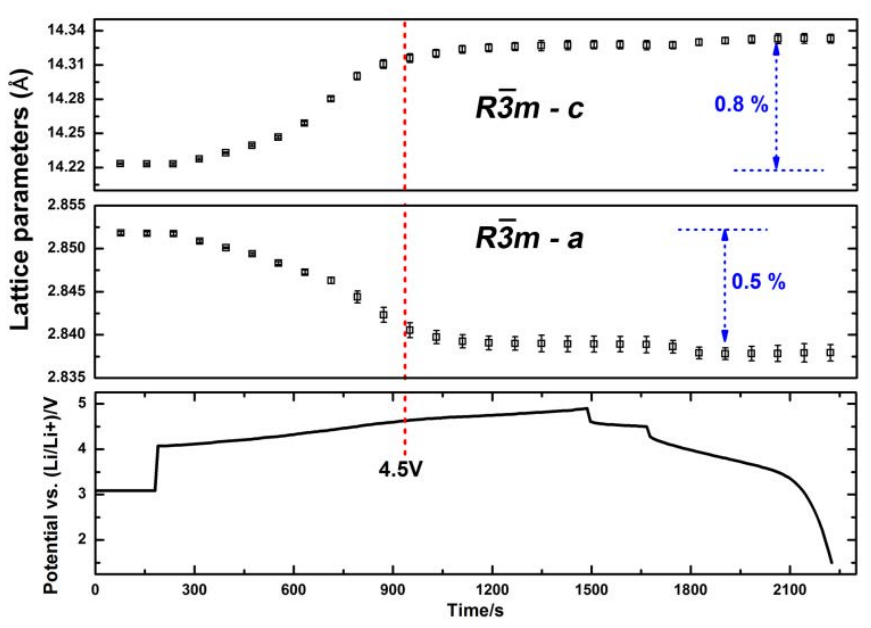

Fig. 10 Evolution of the cell parameters of P-type during $1^{\text {st }}$ cycling at $250 \mathrm{~mA} \cdot \mathrm{g}^{-1}$.

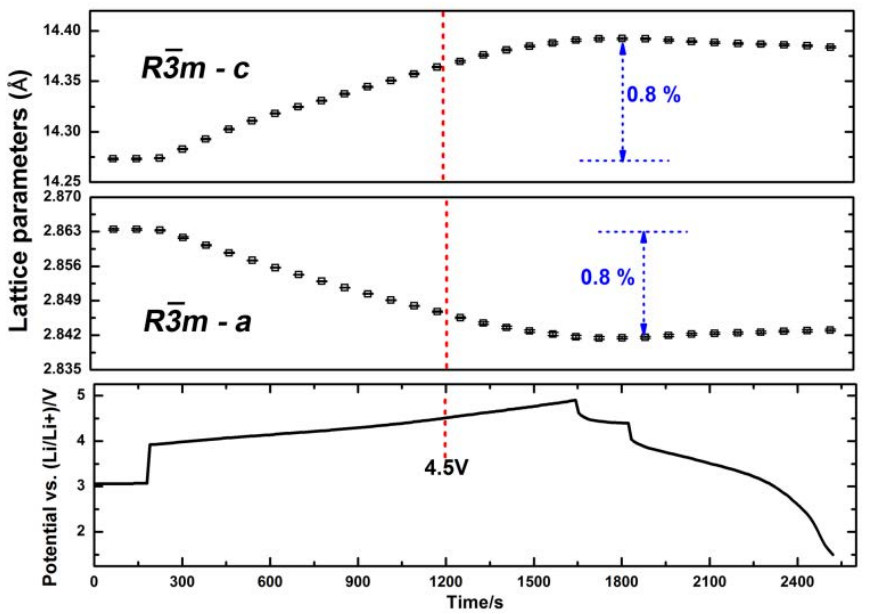

Fig. 11 Evolution of the cell parameters of C-type during $1^{\text {st }}$ cycling at $250 \mathrm{~mA} \cdot \mathrm{g}^{-1}$.

in Li aggregation at particle surface without sufficient time for diffusion into the bulk lattice to take place. Such poor reversibility is quite consistent with the observation of the shortened discharge curve.

Fig. 11 shows the variation of the unit cell parameters $a$ and $c$ of the C-type material when cycled at a high rate of $250 \mathrm{~mA} \cdot \mathrm{g}^{-1}$. It is important to note that following the initial change of both $a$ and $c$ parameters of the $R \overline{3} \mathrm{~m}$ phase at the end of the $4.5 \mathrm{~V}$ plateau, they continue to vary up to the cut-off voltage, suggesting a further removal of Li from the $R \overline{3} \mathrm{~m}$ phase, that is different from P-type. The reason might be that the $\mathrm{Cr}^{3+/ 6+}$ redox reaction continues to contribute electrons and thus varies the lattice constants in this voltage range even at such high current density. Similarly, reintercalation of Li upon fast discharge leads to no obvious change of both lattice parameters, implying a poor reversibility of C-type cathode at a high rate of cycling.Fig. S4 shows the domain size evolution of both samples at the high rate. Initially, in both the P- and Ctype, the domain dramatically reduces from 66 to $30 \mathrm{~nm}$ and 103 to $76 \mathrm{~nm}$, respectively, before reaching $4.5 \mathrm{~V}$, which is in accordance with the trends obtained at the low rate. However, neither of them is able to recover during discharge, indicating poor reversibility of both samples in terms of domain size. Fig.
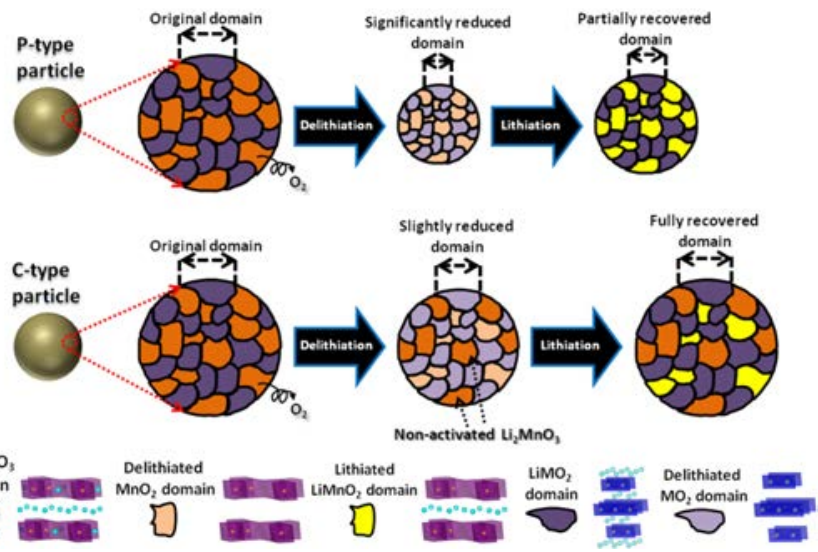

Fig. 12 A schematic illustration of delithiation/lithiation mechanism based on nanodomain structures during $1^{\text {st }}$ cycle at a low rate of cycling.

S5 shows the microstrain variation upon fast charge/discharge. Although both $\mathrm{P}$ - and C-type cathodes present increased microstrain due to deintercalation of $\mathrm{Li}$, their values are relatively steady during the reinsertion of $\mathrm{Li}$. It suggests that in both cases the amount of reinserted Li into the crystal lattice is limited because of the limited diffusion time. It could be concluded that both materials are of poor rate capability based on the above observations.

\section{Discussion: the delithiation/lithiation mechanism}

To represent the main findings more clearly, a schematic illustration is shown in Fig. 12. The initial charging process during the $1^{\text {st }}$ cycle of the P-type [pristine $\mathrm{Li}\left(\mathrm{Li}_{0.2} \mathrm{Mn}_{0.54} \mathrm{Ni}_{0.13} \mathrm{Co}_{0.13}\right) \mathrm{O}_{2}$ ] cathode significantly reduces the domain size due to Li removal. Whilst similar behaviour is observed in the case of C-type [Cr-doped, $\mathrm{Li}\left(\mathrm{Li}_{0.2} \mathrm{Ni}_{0.13}\right.$ $\left.\mathrm{Mn}_{0.54} \mathrm{Co}_{0.03} \mathrm{Cr}_{0.10}\right) \mathrm{O}_{2}$ ] cathode, it progresses to a lesser extent compared to the P-type. Full recovery of domain size as a result of relithiation upon $1^{\text {st }}$ discharge is revealed for the $\mathrm{Cr}$ doped cathode, indicating a better reversibility as Li host after doping, compared to the partial recovery of the pristine cathode. Meanwhile, it seems that although the $R \overline{3} m$-LiMO phase could fully participate in the delithiation reaction in both cathodes, only a partial amount of the $\mathrm{C} 2 / \mathrm{m}-\mathrm{Li}_{2} \mathrm{MnO}_{3}$ phase is activated in case of $\mathrm{Cr}$-doped one, leading to a considerable degree of coexistence between the original $\mathrm{Li}_{2} \mathrm{MnO}_{3}$ and the transformed-LiMnO 2 phases in the local lattice after a full cycle. This finding provides a possible explanation for the mitigated phase transition due to $\mathrm{Cr}$ doping, which confers further benefit during the following cycles.

\section{Conclusions}

We have produced pristine $\mathrm{Li}\left(\mathrm{Li}_{0.2} \mathrm{Ni}_{0.13} \mathrm{Mn}_{0.54} \mathrm{Co}_{0.13}\right) \mathrm{O}_{2}$ and $\mathrm{Cr}$ doped $\mathrm{Li}\left(\mathrm{Li}_{0.2} \mathrm{Mn}_{0.54} \mathrm{Ni}_{0.13} \mathrm{Co}_{0.03} \mathrm{Cr}_{0.10}\right) \mathrm{O}_{2}$ Li-ion battery samples for in operando synchrotron X-ray diffraction studies. These Lirich layered compounds are good cathode materials, as confirmed by the charge/discharge cycling data from loaded coin cells. Most importantly, crystallographic and mechanical 
(domain size and microstrain) information was obtained from SXPD full pattern refinements. The results from the in operando experiment at the low charge rate $\left(50 \mathrm{~mA} \cdot \mathrm{g}^{-1}\right)$ show the remarkable finding that $\mathrm{Cr}$ substitution in the Li-rich layered system has benefits in stabilizing the local structure by suppressing the amount of $\mathrm{Li}_{2} \mathrm{MnO}_{3}$ activation, and thus mitigates the inevitable phase transformation during the $1^{\text {st }}$ cycle. Additionally, the full recovery of lattice domains upon $\mathrm{Li}$ (de)intercalation demonstrates its structural reversibility as $\mathrm{Li}$ host. Nevertheless, the loss of capacity as a result of less $\mathrm{Li}_{2} \mathrm{MnO}_{3}$ activation could be compensated by initiating the $\mathrm{Cr}^{3+} / \mathrm{Cr}^{6+}$ redox reaction, which makes this doped material very promising as a high energy density cathode. Furthermore, the results from the high rate $\left(250 \mathrm{~mA} \cdot \mathrm{g}^{-1}\right)$ cycling experiment reveal a poor rate capability for both pristine and $\mathrm{Cr}$-doped cathodes. More studies on the structural evolution upon extended cycles are in progress for further assessment of the performance of this type of cathode material.

\section{Acknowledgements}

AMK acknowledges funding received for the Multi-Beam Laboratory for Engineering Microscopy (MBLEM) at Oxford through EU FP7 project iSTRESS (604646), and the provision of facilities at the Research Complex at Harwell (RCaH) for the Centre for In situ Processing Studies (CIPS).

\section{Notes and references}

1. M. M. Thackeray, S. H. Kang, C. S. Johnson, J. T. Vaughey, R. Benedek and S. A. Hackney, J. Mater. Chem., 2007, 17, 3112 3125.

2. J. M. Zheng, M. Gu, J. Xiao, P. J. Zuo, C. M. Wang and J. G. Zhang, Nano Lett., 2013, 13, 3824-3830.

3. M. Gu, A. Genc, I. Belharouak, D. P. Wang, K. Amine, S. Thevuthasan, D. R. Baer, J. G. Zhang, N. D. Browning, J. Liu and C. M. Wang, Chem. Mat., 2013, 25, 2319-2326.

4. D. Mohanty, S. Kalnaus, R. A. Meisner, K. J. Rhodes, J. L. Li, E. A. Payzant, D. L. Wood and C. Daniel, J. Power Sources, 2013, 229, 239-248.

5. N. Yabuuchi, K. Yoshii, S. T. Myung, I. Nakai and S. Komaba, J. Am. Chem. Soc., 2011, 133, 4404-4419.

6. A. R. Armstrong, M. Holzapfel, P. Novak, C. S. Johnson, S. H. Kang, M. M. Thackeray and P. G. Bruce, J. Am. Chem. Soc., 2006, 128, 8694-8698.

7. M. Gu, I. Belharouak, J. M. Zheng, H. M. Wu, J. Xiao, A. Genc, K. Amine, S. Thevuthasan, D. R. Baer, J. G. Zhang, N. D. Browning, J. Liu and C. M. Wang, ACS Nano, 2013, 7, 760-767.

8. K. G. Gallagher, J. R. Croy, M. Balasubramanian, M. Bettge, D. P. Abraham, A. K. Burrell and M. M. Thackeray, Electrochem. Commun., 2013, 33, 96-98.

9. J. R. Croy, D. Kim, M. Balasubramanian, K. Gallagher, S. H. Kang and M. M. Thackeray, J. Electrochem. Soc., 2012, 159, A781-A790.
10. M. Sathiya, A. M. Abakumov, D. Foix, G. Rousse, K. Ramesha, M. Saubanere, M. L. Doublet, H. Vezin, C. P. Laisa, A. S. Prakash, D. Gonbeau, G. VanTendeloo and J. M. Tarascon, Nat. Mater., 2015, 14, 230-238.

11. J. M. Zheng, M. Gu, A. Genc, J. Xiao, P. H. Xu, X. L. Chen, Z. H. Zhu, W. B. Zhao, L. Pullan, C. M. Wang and J. G. Zhang, Nano Lett., 2014, 14, 2628-2635.

12. E. S. Lee and A. Manthiram, J. Mater. Chem. A, 2014, 2, 39323939.

13. M. N. Ates, Q. Y. Jia, A. Shah, A. Busnaina, S. Mukerjee and K. M. Abraham, J. Electrochem. Soc., 2014, 161, A290-A301.

14. B. H. Song, C. F. Zhou, H. L. Wang, H. W. Liu, Z. W. Liu, M. O. Lai and L. Lu, J. Electrochem. Soc., 2014, 161, A1723-A1730.

15. S. H. Yu, T. Yoon, J. Mun, S. Park, Y. S. Kang, J. H. Park, S. M. Oh and Y. E. Sung, J. Mater. Chem. A, 2013, 1, 2833-2839.

16. J. Bareno, M. Balasubramanian, S. H. Kang, J. G. Wen, C. H. Lei, S. V. Pol, I. Petrov and D. P. Abraham, Chem. Mat., 2011, 23, 2039-2050.

17. C. H. Shen, Q. Wang, F. Fu, L. Huang, Z. Lin, S. Y. Shen, H. Su, X. M. Zheng, B. B. Xu, J. T. Li and S. G. Sun, ACS Appl. Mater. Interfaces, 2014, 6, 5516-5524.

18. X. Q. Yu, Y. C. Lyu, L. Gu, H. M. Wu, S. M. Bak, Y. N. Zhou, K. Amine, S. N. Ehrlich, H. Li, K. W. Nam and X. Q. Yang, Adv. Energy Mater., 2014, 4

19. L. Simonin, J. F. Colin, V. Ranieri, E. Canevet, J. F. Martin, C. Bourbon, C. Baehtz, P. Strobel, L. Daniel and S. Patoux, J. Mater. Chem., 2012, 22, 11316-11322.

20. S. P. Thompson, J. E. Parker, J. Marchal, J. Potter, A. Birt, F. Yuan, R. D. Fearn, A. R. Lennie, S. R. Street and C. C. Tang, J. Synchrot. Radiat., 2011, 18, 637-648.

21. S. P. Thompson, J. E. Parker, J. Potter, T. P. Hill, A. Birt, T. M. Cobb, F. Yuan and C. C. Tang, Rev. Sci. Instrum., 2009, 80.

22. DIFFRAC PLUS, Version 4.2, Bruker AXS GmbH, Karlsruhe, Germany, 2009.

23. R. W. Cheary and A. Coelho, J. Appl. Crystallogr., 1992, 25, 109-121.

24. M. Sathiya, K. Ramesha, G. Rousse, D. Foix, D. Gonbeau, A. S. Prakash, M. L. Doublet, K. Hemalatha and J. M. Tarascon, Chem. Mat., 2013, 25, 1121-1131.

25. N. Yabuuchi, K. Yamamoto, K. Yoshii, I. Nakai, T. Nishizawa, A. Omaru, T. Toyooka and S. Komaba, J. Electrochem. Soc., 2013, 160, A39-A45.

26. A. K. Padhi, K. S. Nanjundaswamy and J. B. Goodenough, J. Electrochem. Soc., 1997, 144, 1188-1194. 


\section{PCCP}

\section{PAPER}

\section{Graphical Table of Contents}

This paper reports a in operando synchrotron X-ray powder diffraction (SXPD) study on Li-rich $\mathrm{Li}\left(\mathrm{Li}_{0.2} \mathrm{Ni}_{0.13} \mathrm{Mn}_{0.54} \mathrm{Co}_{0.13}\right) \mathrm{O}_{2}$ and $\mathrm{Cr}$-doped $\mathrm{Li}\left(\mathrm{Li}_{0.2} \mathrm{Ni}_{0.13} \mathrm{Mn}_{0.54} \mathrm{Co}_{0.03} \mathrm{Cr}_{0.10}\right) \mathrm{O}_{2}$ cathodes during the first charge/discharge cycle. It was found that $\mathrm{Cr}$-doping benefits in stabilizing local structure by suppressing the activation of $\mathrm{Li}_{2} \mathrm{MnO}_{3}$ domains.

Keywords: in operando synchrotron X-ray powder diffraction, lithium-rich layered cathodes, phase transition, lithium-ion batteries

Title: Mitigated phase transition during first cycle of a Li-rich layered cathode studied by in operando synchrotron X-ray powder diffraction

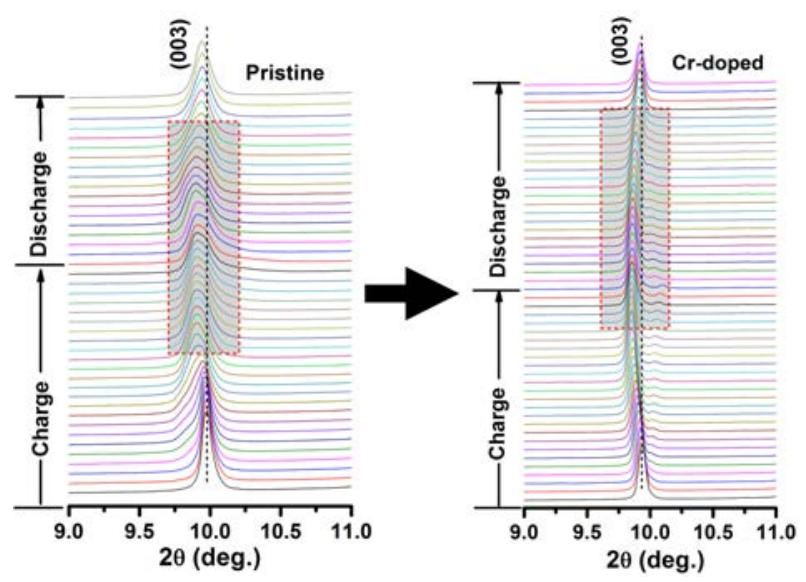

